\title{
Area Code
}

National Cancer Institute

\section{Source}

National Cancer Institute. Area Code. NCI Thesaurus. Code C62138.

A three-dig it Numbering Plan Areas (NPAs) assigned to small divisions of the 19 North

American countries included in the North American Numbering Plan. 